\title{
Stimulating Critical Thinking Skills Through Critical Thinking Question List (CTQL)
}

\author{
Umatul Khoiriyah ${ }^{1 *}$, Uly Pramuditya Isnaini ${ }^{1}$, Rizki Fajar Utami ${ }^{2}$, Nur Aini Djunet ${ }^{2}$, \\ Punik Mumpuni Wijayanti ${ }^{3}$, Fajar Alfa Saputra ${ }^{4}$
}

Department of Medical Education, Faculty of Medicine Universitas Islam Indonesia

${ }^{2}$ Department of Biochemistry, Faculty of Medicine Universitas Islam Indonesia

${ }_{3}^{3}$ Department of Public Health, Faculty of Medicine Universitas Islam Indonesia

${ }^{4}$ Faculty of Medicine, Universitas Islam Indonesia

Corresponding author.Email:umakhoiriyah@uii.ac.id

\begin{abstract}
Critical thinking is an essential skill needed by a physician. One of the ways to learn these skills is using a critical thinking question list (CTQL). This study was aimed to evaluate the effect of CTQL in stimulating students' critical thinking skill in the tutorial Problem-Based Learning (PBL). This study was a cross-sectional study using a mixedmethod approach. The subjects were first-year students who took the first course $(n=177)$. Quantitative data was collected through the score of critical thinking (CT) examination and tutorial performance, while the qualitative data was collected using an open questionnaire. CT score consisted of students' work in applying CTQL based on a reading text. It includes two parts (creating questions and answering them based on a reading text). Students had applied the CTQL method during the first course. Quantitative data was then analysed using Spearman correlation, and the qualitative data was analysed thematically. Tutorial performance correlated significantly with the total CT score ( $\mathrm{p}<$ $0.01)$, and it also had a significant correlation with the CT score part $2(\mathrm{p}<0.01)$. However, CT part 1 did not have a significant correlation with the students' tutorial performance. The qualitative data indicated that CTQL supported students' critical thinking activities during the tutorial, such as: criticising others' opinion, selecting appropriate learning resources, asking more various questions, explaining using their own word, and thinking comprehensively. A critical thinking questions list could be an alternative method to teach critical thinking skills. It could be conducted by stimulating students to create questions and then answer them.
\end{abstract}

Keywords: Critical thinking, question list, CTQL.

\section{INTRODUCTION}

Critical thinking is a generic skill needed by all professions, especially health professions such as a physician. Critical thinking is needed to solve patients' problems. A physician applies critical thinking skills when collecting information about patients' problems (anamnesis), conducting physical and laboratory examinations and making hypotheses through differential diagnosis. Critical thinking also guides a physician always to reevaluate their previous problem solving. A physician also applies critical thinking in determining clinical judgement, which is called clinical reasoning. A physician makes clinical judgment by analysing, synthesis, and evaluating patients' data and correlating it with his/ her knowledge. So, critical thinking is the main element of clinical reasoning [1].

Because of its importance in doctors' work, critical thinking should be stimulated in education programsmany ways to enhance students' critical thinking, such as by group discussion and inquiry-based approach. The previous study showed that the PBL tutorial, which is a type of small group discussion, supports students to apply 
critical thinking. In each step of the PBL tutorial, students apply critical thinking skills [2]. For instance, in defining the main problem, students need to analyse and evaluate the data provided in the case. In reporting the results of self-study, students should explain the new information acquired from self-study in their own words and then correlate it with the case. The other way to stimulate students' critical thinking is by using an inquiry-based approach. Students were asked some specific questions to stimulate them to think deeply and comprehensively [3].

Critical thinking is part of higher-order thinking skill, which is a type of cognitive skill. Based on Bloom's taxonomy, there are six types of cognitive skills such as recalling, comprehension, application, analysis, evaluation and synthesis respectively. In the old version, evaluation is the highest thinking skill, but in the revised version [4], creative thinking is placed on the highest level and the evaluation skill in the fifth level.

Faculty of Medicine Universitas Islam Indonesia (FM UII) makes some innovations to stimulates students critical thinking, one of which is using a critical thinking questions list (CTQL) developed by King [5]. Students are introduced to various questions, each of which could induce specific cognitive skills. For instance, the question "how to apply this matter?" will induce cognitive skill in the level of application. FM UII applies this learning method in the first course of first-year students. It intends to introduce students to various types of cognitive skills and their implementation. The reason for this introduction is that critical thinking skills is an essential component in the PBL tutorial, which is the primary learning activity in FM UII. This study was aimed to evaluate whether there are impacts of learning critical thinking using CTQL on students' PBL tutorial.

\section{METHODS}

\subsection{Context of The Study}

This study was performed at the Faculty of Medicine, Universitas Islam Indonesia that has been implemented Problem-Based Learning (PBL) as the main learning strategies since 2001. Small group discussion or tutorial is the main learning method applied twice or third a week. The tutorial usually applies a seven jumps approach developed by Maastricht. Each unit or module consists of two or third tutorial meetings. In the first meeting, students perform step 1-5 of seven jumps approach, which are: clarifying unfamiliar terms written in the case/problem, defining the problem, analysing the problem using prior knowledge, organising and creating inference the results of step 3, determining the learning objectives. Students then conduct self-study, which is step 6 of the seven jumps approach. In the second meeting, students report their results of self-study to construct collective knowledge with their peers. If this reporting phase does not complete in the second meeting, it will continue in the third meeting.

Tutors facilitate students in the tutorial process and also evaluate student performance using a specific assessment form. The tutorial assessment form in FM UII includes students' responsibility, management of learning resources, communication and critical thinking. This assessment tool has been analysed for its reliability.

\subsection{Participants}

The population of this study was first-year students in the academic year 2020/2021. The subject was selected through total sampling. Subjects who fulfilled the inclusion criteria and did not include in the exclusion criteria will be involved in this study. The inclusion criteria were 1) joining the First course (Introduction 1.1) for the first time, 2) attending all of the skill practice activities, 3) attending all tutorial activities. The exclusion criterion was not completing the evaluation questionnaire distributing at the end of the course. The total subjects were 177 students.

\subsection{Research Design and Analysis}

This study was a mixed-method study using a sequential explanatory design. This study has been approved by the Ethics Committee of FM UII with Approval number 27/Ka.Kom.Et/70/KE/XI/2020. The quantitative data was collected through academic data recorded by the academic office. It consisted of students' tutorial performance and critical thinking score in the skills practice examination. Students tutorial performance and critical thinking score range from 1100. Critical thinking score was obtained from students score in worksheet 1 and 2, consisting of critical thinking question list and cognitive level as explained in the background. In Part 1, students' provided a reading text and five questions based on this text. Students had to answer these questions and then determine the cognitive level of their answer based on revised Bloom's taxonomy. The score of this part ranges from 0-30. In part 2 , Students were also given a reading text. Students then created questions and their answers at each cognitive level. The score in this part is $0-70$. So the maximum score for all parts is 100 . The qualitative data was obtained through the students answer in the course evaluation form (open questionnaire) that usually was 
distributed to the students at the end of each course in FM UII. The quantitative data was analysed using Pearson correlation, while the qualitative data was analysed thematically. The inference was then conducted based on the results of these analyses.

\section{RESULTS}

\subsection{Quantitative Data}

There are 177 students that fulfil the criteria to be participants in this study. The students' critical thinking score and tutorial performance are described in Table 1.

Table 1. The critical thinking score and tutorial performance

\begin{tabular}{|l|c|c|c|c|}
\hline Score & Min & Max & Mean & $\begin{array}{l}\text { Stand } \\
\text { ard } \\
\text { deviat } \\
\text { ion }\end{array}$ \\
\hline CT Part1 & 5 & 30 & 24.4 & 5.7 \\
\hline CT Part 2 & 19 & 70 & 56.9 & 9.9 \\
\hline Total CT & 42 & 100 & 81.1 & 12.8 \\
\hline $\begin{array}{l}\text { Tutorial } \\
\text { performance }\end{array}$ & 64.6 & 96.2 & 80.8 & 6.2 \\
\hline
\end{tabular}

As explained in the method section, critical thinking examination consisted of two parts. In CT part 1 , the mean is 24.4 ( $81.3 \%$ of the maximum score). Some students got a maximum score in this part, which is 30 . In The CT part 2, there were also some students who achieved a maximum score (70). The mean of CT part 2 is 56.9 ( $81.2 \%$ of the maximum score), and the minimum score is 19 . Table 1 also describes that the mean of the CT total score is 81 , and tutorial performance is 80.8 . There were no students who obtained a maximum score (100) in their tutorial performance.

The results of the correlation analyses (Table 2) showed that there was a significant correlation between the total score of critical thinking and tutorial performance $(\mathrm{p}<0.01)$ with $\mathrm{r}=0.205$ (weak correlation). A similar result was also shown by the correlation of CT score Part2 and tutorial performance. The correlation is significant with $\mathrm{r}=0.201$. However, there was no significant correlation between the CT score part1 and tutorial performance $(\mathrm{p}>0.01)$
Table 2. The correlation between critical thinking and tutorial performance

\begin{tabular}{|l|l|l|l|l|l|l|}
\hline Score & \multicolumn{2}{|c|}{ Significance (2-taled) } & \multicolumn{4}{|c|}{ Correlation Coefficient } \\
\hline $\begin{array}{l}\text { Tutorial } \\
\text { perform } \\
\text { ance }\end{array}$ & $\begin{array}{l}\text { CT } \\
\text { part1 }\end{array}$ & $\begin{array}{l}\text { CT } \\
\text { part 2 }\end{array}$ & $\begin{array}{l}\text { Total } \\
\text { CT }\end{array}$ & $\begin{array}{l}\text { CT } \\
\text { part1 }\end{array}$ & $\begin{array}{l}\text { CT } \\
\text { part 2 }\end{array}$ & Total CT \\
\cline { 2 - 8 } & 206 & .007 & .00 & .096 & .201 & .205 \\
\hline
\end{tabular}

\subsection{Qualitative Data}

The qualitative data was obtained from students' answers on the evaluation form. Students perceived that the method to learn critical thinking using CTQL supported their tutorial activities. This learning method could enhance their critical thinking skills during tutorial, especially in: 1) asking more various questions, 2) explaining using their own word 3) criticising others' opinion, 4) thinking comprehensively, 5) selecting appropriate learning resources.

Students described that CTQL assisted them to have the capability in creating various questions during the tutorial. They did not only ask surface questions but also could ask various questions at different cognitive levels.

"The benefit is I could determine the level of my question in the tutorial, understand the problem occurred, and by using this created question we could search the appropriate answer based" (Student 72)

Students also explained that by learning critical thinking through CTQL, they could explain the knowledge acquired during self-study by their own world. Using CTQL, they learned to answer questions in their own words, especially for the questions that needed the answers in cognitive level 2 (comprehension) and above. An example of a student statement is: "We could analyse and explain the material using our own word" (Student 166).

The other benefit that students gained from learning critical thinking using CTQL is that students became able to criticise others' opinions during the tutorial. They did not directly receive other's opinion, but they evaluate it first to know whether other's opinion is true or not.

"It is very useful. When we get some information, we do not agree spontaneously since we are able to ask its validity using our critical thinking "(Student 56).

Students also experienced that learning critical thinking using CTQL stimulated them to think comprehensively. They could view the problems from many perspectives. Moreover, CTQL supported them to 
think systematically and to be a more creative person in solving the problems in the tutorial.

"Learning critical thinking by creating questions and their answers based on each cognitive level stimulates us to be systematic, logic and objective thinking. So, we are able to create a lot of new ideas, to become more creative and efficient in solving a problem "(Student 165)

Lastly, students were also able to select appropriate learning resources that align with their learning needs. They could criticise whether a book or a journal could fulfil their learning objective in tutorials.

"It is beneficial to provide literature and reading skills and to understand a material" (Student 60).

"By learning critical thinking, I could explore various learning resources "(Student 158)

\section{DISCUSSIONS}

The results show that the mean of students' critical thinking examination scores is good. Both of these are above $80 \%$ of the achievement. This indicates that learning critical thinking using CTQL is an effective method to enhance students' understanding of various types of cognitive skills and the appropriate ways to implement them. This finding is in line with the previous research conducted by Velde et al. [6], who applied CTQL (King's question technique) on occupational therapy students during a large class. This study showed that students in the experimental group, who applied CTQL, asked more high-level questions than the control group.

The correlation of total critical thinking score and tutorial performance shows a significant relationship. This means that students apply critical thinking in the PBL tutorial. In each step of the seven jumps, students apply different thinking skills [7]. On other hand, learning critical thinking also assists students to perform better in the tutorial. In the qualitative data, students experienced various benefits of learning critical thinking using CTQL. Students described that the CTQL could assist their performance in the tutorial, especially in applying critical thinking. Students have more ability in creating questions that have more relevance to the explanation of their peers. This condition indicates that CTQL is an effective method to stimulate students in understanding each type of questions and the ways to use it. Inquiries are basic critical thinking skills. Students who could ask good questions usually have good critical thinking skills [5].
The results also show that learning critical thinking using CTQL enhance students to apply critical thinking skill such as analysing the information and thinking comprehensively. During learning activities using CTQL, students were stimulated to create answers in each cognitive level of the revised Bloom taxonomy. They became familiar with the type of statement or explanation in each cognitive level, such as analysing statements. They also had more understanding of the type of answer or statement that only induced low order thinking, such as recalling or comprehension. This finding is in line with previous research conducted by Kong et al. showing that inquiry or questions will enhance the quality of PBL tutorials [2] .

The data shows that the correlation between each part of critical thinking examination and tutorial performance is only significant in Part 2. Critical thinking score part 1 does not have a significant relationship. This might happen because in critical thinking part 2, students only answered the provided question and then determined the cognitive level based on the revised Bloom taxonomy. In Part 2, students needed to create their own question and its answer at each cognitive level. In this part, students thought harder since they should think of the specific questions in each cognitive level by themselves and then determine its answer based on the reading text. So in part 2 , students applied more thinking skills than in part 2 .

The strength of the study is related to the design that uses a mixed-method approach. The data is rich because it is viewed and analysed from quantitative and qualitative data. The limitation of this study is that it is only applied to one institution.

\section{CONCLUSSIONS}

A critical thinking question list (CTQL) could stimulate students' critical thinking skill. Students are able to ask various questions, to analyse information, to criticise the opinions of others, to think systematically and comprehensively and to select appropriate learning resources. Learning critical thinking in CTQL enhance students' performance in tutorial

\section{AUTHORS' CONTRIBUTIONS}

UK designing, analysing the data and drafting, UPI, RFU, FAS, NAD and PMW assisting in designing the study and collecting the data. 


\section{ACKNOWLEDGMENTS}

The author wants to thank FM UII that has provided funding and facilitated the authors to access the academic data.

\section{REFERENCES}

[1]. Duchscher, J.E.B., Catching the wave: understanding the concept of critical thinking. Journal of Advanced Nursing, 1999. 29(3): p. 577-583.

[2]. Kong, L.-N., Qin B., Zhou Y-q., Mou S-y., Gao $\mathrm{H}-\mathrm{M}$ et al., The effectiveness of problem-based learning on development of nursing students' critical thinking: A systematic review and metaanalysis. International Journal of Nursing Studies, 2014. 51(3): p. 458-469.

[3]. Merisier, S., C. Larue, and L. Boyer, How does questioning influence nursing students' clinical reasoning in problem-based learning? A scoping review. Nurse Education Today, 2018. 65: p. 108-115.

[4]. Krathwohl, D.R., A Revision of Bloom's Taxonomy: An Overview. Theory Into Practice, 2002. 41(4): p. 212-218.

[5]. King, A., Inquiring minds really do want to know: Using questioning to teach critical thinking. Teaching of Psychology, 1995. 22(1): p. 13-17.

[6]. Velde, B.P., P.P. Wittman, and P. Vos, Development of critical thinking in occupational therapy students. Occupational Therapy International, 2006. 13(1): p. 49-60.

[7].. Khoiriyah, U., G.R. Rahayu, and T. Prihatiningsih. Critical thinking in problem based learning tutorials. in 9 th Asia Pacific Medical Education Conference. 2009. Singapore NUS Yong Loo Lin School of Medicine 